\title{
SAÚDE E DIREITO À INFORMAÇÃO: O PROBLEMA DOS AGROTÓXICOS NOS ALIMENTOS
}

Health and the right to information: the problem of pesticide presence in food

${ }^{1}$ Universidad Nacional de Buenos Aires. Buenos Aires, Argentina.

Correspondência: Tarcisio Miguel Teixeira. E-mail: tarcisio.teixeira@ifpr.edu.br.

Recebido em: 23/11/2015. Revisado em: 29/02/2016. Aprovado em: 02/03/2016. 
Saúde e direito à informação: o problema dos agrotóxicos nos alimentos

\section{RESUMO}

$\mathrm{O}$ artigo analisa o problema atual da presença de agrotóxicos nos alimentos sob a vertente da falta de informação a respeito dos produtos aplicados nos alimentos para sua produção. Estabelece como pressuposto a relação diretamente proporcional entre saúde e alimentação saudável e o direito fundamental de ser informado sobre a qualidade dos alimentos. Conclui com hipóteses e discussão sobre as razões da falta dessa informação nos produtos alimentícios comercializados in natura.

\section{Palavras-Chave:}

Agrotóxicos; Contaminação dos Alimentos; Direito à Informação; Direito à Saúde.

\section{ABSTRACT}

This article analyses the current problem of pesticide presence in food from a perspective of a lack of information about products used in food production. The article establishes the assumptions of a directly proportional relationship between health and healthy eating, and the basic right of being informed about the food quality. It concludes with hypothesis and discussion on the reasons for this lack of information on the preparation of in natura food products.

\section{Keywords:}

Food Contamination; Pesticides; Right to Health; Right to Information. 


\section{Introdução}

Segundo o Manual clínico de alimentação e nutrição: na assistência a adultos infectados pelo HIV, uma alimentação saudável deve ser: acessível física e financeiramente, saborosa, variada, colorida, harmoniosa e segura. Esta última característica significa: "os alimentos que compõem a alimentação devem ser seguros, livres de contaminação físico-química, biológica ou genética, evitando possíveis riscos que podem causar à saúde das pessoas e da coletividade"1. Portanto, alimento saudável, necessariamente, deve estar livre da contaminação com agrotóxicos. Este trabalho enfocará exclusivamente este quesito: alimentos que atualmente são inseguros por apresentarem contaminação com agrotóxicos que não é informada ao consumidor.

O crescimento populacional e a tentativa de elevar a qualidade alimentar dos povos promoveu um efeito exponencial na produção de alimentos no mundo inteiro. Obviamente que apenas aumentar o plantio não seria a solução para obter esse aumento na quantidade de alimentos. As técnicas e os recursos para produção também sofreram profundas transformações. Entre os principais recursos, destaca-se o uso de agrotóxicos para controlar plantas que competem com as culturas, microrganismos e insetos. Entretanto, esses compostos não são inócuos para a natureza e os seres humanos, e o contato com eles ou ingestão deles promove graves intoxicações.

São contaminados comumente os produtores, pelo contato nas aplicações, e muitos consumidores, que ingerem doses crônicas dos agrotóxicos que são aplicados sem os devidos cuidados.

A razão desse intenso uso de agrotóxicos deve-se ao modelo monocultural adotado pela agricultura moderna - modelo que favorece os desequilíbrios populacionais de plantas invasoras, doenças e pragas, reforçando a cada ano a necessidade de uma quantidade maior de agrotóxicos.

Santilli destaca que:

A agricultura interage com o ambiente de diversas formas que afetam a saúde humana. Os efeitos nocivos do uso indiscriminado de agrotóxicos são bem conhecidos. Em casos extremos, chegam a provocar anomalias genéticas, tumores e câncer. A OMS estima que ocorrem no mundo cerca de três milhões de intoxicações agudas por agrotóxicos, com 220.000 mortes por ano, das quais cerca de $70 \%$ ocorrem em países em desenvolvimento. Além da intoxicação de trabalhadores rurais que têm contato direto ou

${ }^{1}$ BRASIL. Ministério da Saúde. Secretaria de Vigilância em Saúde. Programa Nacional de DST/AIDS. Manual clínico de alimentação e nutrição na assistência a adultos infectados pelo HIV / Ministério da Saúde, Secretaria de Vigilância em Saúde, Programa Nacional de DST/Aids. - Brasília: Ministério da Saúde, 2006. p. 15. (Série A. Normas e Manuais Técnicos). 
indireto com esses produtos, a contaminação de alimentos atinge também os consumidores ${ }^{2}$.

A situação dos agrotóxicos nos alimentos pode ser entendida como os efeitos colaterais do modelo produtivo da Revolução Verde e demonstra "a relevância das condições ambientais essenciais para a concretização dos direitos à vida, à propriedade e à saúde"3.

Enfim, o problema da contaminação dos alimentos in natura por agrotóxicos é uma questão premente, a ser resolvida ou ter alternativas que minimizem suas consequências, garantindo-se os direitos fundamentais à saúde, à informação e à alimentação adequada.

\section{Metodologia}

$\mathrm{O}$ artigo será desenvolvido em quatro etapas básicas. O primeiro será a apresentação da pesquisa desenvolvida por Flávia Galinda e Fátima Portilho, que identifica a preocupação de grupos de consumidores em relação à contaminação dos alimentos com agrotóxicos. Em seguida expõem-se os dados da pesquisa da Agência Nacional de Vigilância Sanitária do Brasil (Anvisa) a respeito dos alimentos contaminados com agrotóxicos que são comercializados normalmente no Brasil. No terceiro estágio, serão desenvolvidos os argumentos jurídicos (constitucionais, infraconstitucionais e de direito internacional) que amparam os direitos fundamentais em questão: os direitos à alimentação adequada, à saúde e à informação da qualidade dos alimentos. Finalmente, são indicadas as soluções possíveis para o mal silencioso que é a intoxicação crônica.

\section{Percepção do risco por parte dos consumidores}

Galinda e Portilho, baseando-se em coleta de dados discursivos com a técnica densa de grupo focal, constaram que,

embora as pessoas já tenham ouvido falar nos possíveis perigos do consumo de alimentos com agrotóxicos ou transgênicos, ainda não inserem tais riscos em seus repertórios de preocupação, de natureza privada e pública, nem em suas práticas cotidianas associadas à alimentação. Se há risco, este não é tangibilizado pelo consumidor e, portanto, mostra-se invisível ${ }^{4}$.

\footnotetext{
2SANTILLI, Juliana. Agrobiodiversidade e direitos dos agricultores. 2009. Tese (Doutorado) - Pontifícia Universidade Católica, PUC/PR, Curitiba, 2009. p. 77.

${ }^{3}$ CARVALHO, Délton Winter de. A sociedade do risco global e o meio ambiente como um direito personalíssimo intergeracional. Revista de Direito Ambiental, São Paulo, v. 13, n. 52, p. 27-36, out./dez. 2008.

${ }^{4}$ GALINDO, Flávia; PORTILHO, Fátima. O Peixe Morre pela Boca: como os consumidores entendem os riscos dos agrotóxicos e dos transgênicos na alimentação. Sustentabilidade em Debate, Brasília, v. 6, n. 2, p. 77, maio/ago 2015.
} 
Este resultado torna o problema em questão muito mais preocupante, pois a presença dos agrotóxicos nos alimentos pode ser tratada como um risco "invisível" e, além disso, não está despertada nos consumidores a real dimensão dos riscos. Ou seja, não há ação concreta por parte do Estado, e os próprios consumidores estão alienados sobre o que estão ingerindo diariamente.

Por fim, concluíram as pesquisadoras:

A discussão acima evidencia que, mesmo reconhecendo os perigos associados aos agrotóxicos, as digressões voltavam à questão dos nutrientes, deixando os riscos dos alimentos com agrotóxicos em segundo plano. A pesquisa mostrou que os indivíduos usam todo seu sistema sensorial na busca de proteção aos riscos: cheiram e apertam os alimentos, cozinham a carne de porco por horas ou evitam comê-la na rua, enfim, criam e reproduzem hábitos que visam à purificação dos alimentos. Em alguns casos, os indivíduos optam por cortar certos alimentos de sua dieta. Todavia, esta pesquisa mostrou a baixa preocupação das famílias com possíveis contaminações dos alimentos por agrotóxicos e transgênicos ${ }^{5}$.

\section{Resultados do Programa de Análise de Resíduos de Agrotóxicos em Alimentos (PARA)}

A Anvisa iniciou em 2003 o Programa de Análise de Resíduos de Agrotóxicos em Alimentos (PARA), que visa a avaliar e promover a qualidade dos alimentos em relação aos agrotóxicos. O programa consiste em coletar amostras dos principais alimentos consumidos pelos brasileiros e realizar avaliações toxicológicas neles, indicando resultados do uso de agrotóxicos não recomendados para a respectiva cultura e uso de produto permitido, mas acima do limite máximo. Por fim, é publicado um relatório anual das pesquisas ${ }^{6}$.

O programa tem dados desde 2001, mas, para a análise deste artigo, serão utilizados os resultados de 2010, 2011 e 2012, que se encontram disponíveis no site oficial da Anvisa ${ }^{7}$.

No relatório publicado em 2010, encontra-se uma gama considerável de produtos para consumo in natura com aplicações de agrotóxicos não liberados para a cultura e em doses acima do permitido. São destaques: a alface, com 54,20\% de resultados insatisfatórios; a cenoura, com 49,60\%; o morango $(63,40 \%)$; o pepino

\footnotetext{
${ }^{5}$ GALINDO, Flávia; PORTILHO, Fátima. op. cit. p. 83.

${ }^{6}$ ANVISA. Programa de Análise de Resíduos de Agrotóxicos em Alimentos: relatório de atividades de 2011 e 2012. Brasília, 29 out. 2013. p. 5.

${ }^{7}$ ANVISA. Programa de Análise de Resíduos de Agrotóxicos em Alimentos: relatório de atividades de 2010. Brasília, 05 dez. 2011.
} 
(57,40\%); e o pimentão $(91,80 \%)^{8}$. Em 2011, mantiveram-se críticos: a alface (43\%), a cenoura (67\%), o pepino (44\%) e o pimentão (90\%) ${ }^{9}$. Os dados de 2012 apresentaram o abacaxi, com $41 \%$, a cenoura (33\%), o morango (59\%) e o pepino $(42 \%)^{10}$.

Observa-se, pelos resultados obtidos nas pesquisas, que há uma contaminação crônica dos alimentos que chegam à mesa dos brasileiros, pois os produtos agrícolas estudados são de uso in natura ou passarão por um processo simples de cocção em seu preparo.

A primeira questão a ser discutida é de caráter toxicológico, pois implica saber o quanto esses produtos poderão provocar males à saúde dos consumidores. Lógico que, havendo uma extrapolação das quantidades permitidas e do uso de produtos indevidos para as respectivas culturas, alguma consequência maléfica podemos expectar para o organismo dos consumidores dessas olerícolas e grãos avaliados. Entretanto, este não é o foco deste artigo, pois a análise será sobre o direito de informação que vem sendo negligenciado aos consumidores - o direito de saberem quais agrotóxicos, mesmo que legalmente permitidos e nas doses corretas, são aplicados nos produtos que eles irão consumir.

É interesse fazer uma comparação entre a extensa normatização que existe para as informações nutricionais que devem ser dispostas nos rótulos dos alimentos e as informações sobre os agrotóxicos que são negligenciadas aos consumidores. A justificativa para o zelo de informações nutricionais é a saúde do consumidor, que poderá decidir quais alimentos irá consumir e que não comprometem sua saúde. Esse fornecimento de informações nutricionais não é exclusividade do Brasil: no Mercado Comum do Sul, por meio do Regulamento técnico Mercosul sobre informação nutricional complementar, padronizam-se as informações que os Estados-Partes da entidade supranacional devem adotar em seus rótulos ${ }^{11}$. Também, ao observarmos qualquer produto alimentar embalado de circulação mundial, notamos a presença dessas informações nutricionais. Entretanto, especificamente no Brasil, não são fornecidos ao consumidor os dados sobre quais produtos agroquímicos foram aplicados nos alimentos que irá ingerir (lembrando que agrotóxicos são produtos extremamente perigosos para a saúde humana).

Outra comparação salutar é feita com as bulas de medicamentos, que apontam as recomendações restritivas, indicando que a pessoa não faça uso do medicamento caso tenha alergia aos princípios ativos ali contidos.

Não obstante, o consumidor de alimentos não tem direito às mesmas informações referentes aos agrotóxicos. Ele pode, inclusive, consumir alimentos com

\footnotetext{
${ }^{8}$ ANVISA. Programa de Análise de Resíduos de Agrotóxicos em Alimentos: relatório de atividades de 2010, cit. ${ }^{9}$ ANVISA. Programa de Análise de Resíduos de Agrotóxicos em Alimentos: relatório de atividades de 2011 e 2012, cit., p. 19.

${ }^{10}$ d. Ibid., p. 31.

${ }^{11}$ ANVISA. Resolução da Diretoria Colegiada n. 54, de 12 de novembro de 2012. Dispõe sobre o Regulamento Técnico sobre Informação Nutricional Complementar. Disponível em: <http://portal. anvisa.gov.br/documents/\%2033880/2568070/rdc0054_12_11_2012.pdf/c5ac23fd-974e-4f2c-9fbc48f7e0a31864>. Acesso em: 31 jan. 2017.
} 
níveis aceitos de um determinado princípio ativo, mas que lhe provoquem alguma reação alérgica. Além disso, não se pode esquecer do possível efeito de acúmulo dos resíduos metabólicos do agrotóxico no organismo (magnificação trófica).

\section{A fundamentalidade do direito à alimentação adequada}

Antes de iniciar o tratamento formalizado dos direitos humanos e fundamentais, é importante lembrar o fato histórico ocorrido nos debates em Assembleia entre nobreza, clero e Terceiro Estado na França revolucionária de 1789, em que prevaleceu a ideia de que deveria haver uma declaração preliminar de direitos e estes norteariam o texto constitucional ${ }^{12}$. Essa visão histórica permite vislumbrar que os precursores das gerações dos direitos humanos estabeleceram uma sequência entre os direitos, propriamente ditos, e a Constituição. Os direitos em si são precedentes ou pré-existentes, e devem ser descobertos ou entendidos pela humanidade. A Constituição seria, então, o texto aprovado na tentativa de expressar tais direitos e, por isso, não tem seu real valor na mera literalidade, mas sim no espírito legal que comporta esses direitos, ou em linhas jurídicas: a Constituição é essencialmente principiológica e, por isso, ao longo do tempo, a aceitação e a efetivação desses direitos devem ser ampliadas, mesmo quando em estado implícito na Carta Magna.

\section{Segundo Lopes e Chehab,}

Seguidamente, apresentou-se o direito à alimentação adequada, entendido como o acesso físico e econômico à alimentação em quantidade e qualidade necessárias para uma vida saudável, sendo considerado como um direito fundamental, não apenas pela indireta previsão formal na Constituição Federal de 1988, mas devido especialmente pela sua importância material, enquanto instrumental de proteção da dignidade do ser humano ${ }^{13}$.

Segundo as mesmas autoras, constitucionalmente o Brasil não expressou explicitamente o direito à alimentação adequada. Entretanto, por força do parágrafo $2^{\circ}$ do artigo $5^{\circ}$ da Constituição Federal de 1988 (CF/88), pode-se confirmar sua presença entre os direitos fundamentais: "Os direitos e garantias expressos nesta Constituição não excluem outros decorrentes do regime e dos princípios por ela adotados, ou dos tratados internacionais em que a República Federativa do Brasil seja parte"14.

\footnotetext{
${ }^{12}$ MARUM, Jorge Alberto de Oliveira. Meio ambiente e direitos humanos. Revista de Direito Ambiental, v. 28, out./dez. 2002.

${ }^{13}$ LOPES, Ana Maria D'Avila; CHEHAB, Isabelle Maria Vasconcelos. A construção do direito fundamental à alimentação adequada no nordeste brasileiro. Revista de Direito Constitucional e Internacional, n. 68, p. 19-41, jul./set. 2009. p. 86.

${ }^{14}$ BRASIL. Constituição da República Federativa do Brasil de 1988. Disponível em: <http://www.planalto.gov. br/ccivil_03/constituicao/constituicaocompilado.htm>. Acesso em: 31 jan. 2017.
} 
O legislador constituinte, ao descrever "do regime e dos princípios por ela adotados", deixa claro que a interpretação topográfica, que tenta represar os direitos fundamentais à lista do artigo $5^{\circ}$, não deve ser utilizada para esta Constituição. Portanto, esparsos e implícitos na $\mathrm{CF} / 88$ existem outros direitos fundamentais, não de importância secundária, mas essenciais para o exercício da essencialidade da dignidade humana ${ }^{15}$.

Seguindo a lista elaborada por Lopes e Chehab ${ }^{16}$, encontram-se na CF/88: "Art. 10 A República Federativa do Brasil, formada pela união indissolúvel dos Estados e Municípios e do Distrito Federal, constitui-se em Estado Democrático de Direito e tem como fundamentos: [...] III - a dignidade da pessoa humana; [...]".

Este fundamento - leia-se princípio constitucional - está intrinsicamente ligado ao direito à alimentação adequada. Não há forma de promover a dignidade humana ao ápice possível em uma sociedade que relegue a alimentação de seus membros para um segundo plano, ou ainda que pressuponha as ganâncias de grupos econômicos acima desse direito.

Ainda no arrolamento de Lopes e Chehab, encontra-se:

Art. $3^{\circ}$ Constituem objetivos fundamentais da República Federativa do Brasil: I - construir uma sociedade livre, justa e solidária; II - garantir o desenvolvimento nacional; III - erradicar a pobreza e a marginalização e reduzir as desigualdades sociais e regionais; IV - promover o bem de todos, sem preconceitos de origem, raça, sexo, cor, idade e quaisquer outras formas de discriminação ${ }^{17}$.

As autoras escolheram os incisos I e II para justificar a fundamentalidade constitucional do direito à alimentação adequada. Todavia, salvo melhor juízo, é observável que todos os objetivos fundamentais da República estão interligados ao direito fundamental da alimentação adequada, pois:

(a) Estar em uma sociedade dita de homens livres, mas condicionados a uma situação de fome ou alimentação inadequada é uma falácia. Estar em condições fisiológicas homeostáticas dos devidos nutrientes é parte da essencialidade material para suas livres escolhas. José Claudio Monteiro de Brito Filho, procurador do trabalho, afirma serem "a falta de condições mínimas de trabalho,

\footnotetext{
${ }^{15} \mathrm{~A}$ Emenda Constitucional n. 90/2015 formalizou o direito à alimentação como direito social. "Artigo único. 0 art. $6^{\circ}$ da Constituição Federal de 1988 passa a vigorar com a seguinte redação: "Art. $6^{\circ}$ São direitos sociais a educação, a saúde, a alimentação, o trabalho, a moradia, o transporte, o lazer, a segurança, a previdência social, a proteção à maternidade e à infância, a assistência aos desamparados, na forma desta Constituição.". BRASIL. Emenda Constitucional n. 90, de 15 de setembro de 2015. Dá nova redação ao art. $6^{\circ}$ da Constituição Federal, para introduzir o transporte como direito social. Disponível em: <http://www. planalto.gov.br/ccivil_03/constituicao/emendas/emc/emc90.htm>. Acesso em: 31 jan. 2017.

${ }^{16}$ LOPES, Ana Maria D’Avila; CHEHAB, Isabelle Maria Vasconcelos. op. cit. p. 98.

${ }^{17}$ Id. Ibid. p. 99.
} 
de moradia, higiene, respeito e alimentaçãa ${ }^{18}$ " (destaque do autor) conjunturas degradantes de trabalho. Situação que, segundo o artigo 149 do Código Penal Brasileiro, reduz a pessoa à condição análoga à de escravo ${ }^{19}$.

(b) A justiça, segundo Ronald Dworkin, é pertencente à dimensão interpretativa da humanidade e, portanto, deve ser feita considerando-se sua existência dentro das estruturas sociais contemporâneas. Portanto, sociedade justa vai além da mera comparação igualitária superficial defendida na definição metafísica de justiça ${ }^{20}$. No caso específico da alimentação, a sociedade será justa não somente com satisfação superficial da produção em quantidade per capta proporcional, mas respeitando também a saúde dos produtores e não lançando mão de produtos de boa aparência, mas contaminados de veneno com a justificativa de que precisam suprir o que o mercado exige.

(c) Os exemplos históricos demonstram que a produção agrícola foi a base econômica do desenvolvimento e do declínio de grandes nações ${ }^{21}$, e mesmo uma forma de dominação - como relata o historiador Flavio Josefo na aquisição de terras pelo Faraó, seguindo as orientações de José, filho de Jacó, e instituindo a cobrança da taxa de usufruto da quinta parte da produção ${ }^{22}$. Entretanto, sua função é produzir o necessário para a satisfação e a nutrição das pessoas, e não ser definida pelas "leis de mercado", desconsiderando a saúde dos consumidores como quesito essencial para decidir sobre as formas de produção (também se estabelece nesse processo a função social da propriedade). Portanto, a República Federativa do Brasil cumpre com a solidariedade ao fiscalizar e informar sobre a qualidade dos alimentos que chegam às mesas dos brasileiros.

(d) O posicionamento topográfico do desenvolvimento nacional em objetivos da República Federativa do Brasil não o excluiu do grupo dos direitos (fundamentais). Ao contrário, é um direito (social, coletivo e individual) e também uma obrigação estatal direcionar suas atuações para se manter em constante desenvolvimento. Segundo Gustavo Henrique Justino de Oliveira, definir desenvolvimento é um trabalho de alta complexidade e esse conceito

\footnotetext{
${ }^{18} \mathrm{O}$ autor, nesse quesito, foca alimentação provavelmente como quantidade. Entretanto, como estudado acima, a alimentação adequada é mais do que quantidade (volume), ou mesmo quantidade de nutrientes. A ausência de substâncias tóxicas é essencial para sua qualidade. BRITO FILHO, José Claudio Monteiro de. Trabalho com redução do homem à condição análoga à de escravo e dignidade da pessoa humana. Texto revisto e com alterações. Publicado originalmente na Revista Genesis, Curitiba, n. 137, p. 673-682, maio. 2004. Disponível em: <http://pgt.mpt.gov.br/publicacoes/escravo/dignidade-trabalhoescravo.pdf>. Acesso em 16 fev. 2017. p. 13.

${ }^{19}$ Id. Ibid.

${ }^{20}$ ABBOUD, Georges; CARNIO, Henrique Garbellini; OLIVEIRA, Rafael Tomaz de. Introdução à teoria e à filosofia do direito. 2. ed. São Paulo: Thomson Reuters, 2014. p. 200-205.

${ }^{21}$ VEIGA, José Eli. Crescimento, agricultura e meio-ambiente. In: ENCONTRO NACIONAL DE ECONOMIA, 15. Anais... Recife, 1997. v. 2, p. 900-939.

${ }^{22}$ JOSEFO, Flavio. Antiguidades judaicas. São Paulo: Paulus Ed., 2001. Livro primeiro. Capítulo IV.
} 
não será abordado neste artigo. Entretanto, segundo o autor, a efetivação do desenvolvimento tem fortes implicações para os direitos sociais, econômicos, culturais e ambientais ${ }^{23}$. Ora, com a Emenda Constitucional n. 90/2015, o direito à alimentação foi introduzido na lista de direitos sociais do artigo $6^{\circ}$, o que estabelece a relação direta e escrita entre o desenvolvimento nacional e a necessidade de uma alimentação adequada.

(e) $\mathrm{O}$ inciso III do artigo $3^{\circ} \mathrm{da} \mathrm{CF} / 88$ estabelece o objetivo de erradicar a pobreza, e um dos sintomas da pobreza é a alimentação insuficiente ou inadequada. Neste caso específico, os consumidores podem não estar privados de condições financeiras mínimas para adquirir os alimentos, mas ficam submetidos à situação de não poderem escolher alimentos de qualidade, igualando-se à situação de pobreza.

(f) Enfim, o último inciso objetiva promover o bem de todos, e isso implica satisfazer aqueles que são os direitos fundamentais para concretização de sua dignidade, como os direitos à alimentação adequada, à informação e à saúde.

O caput do artigo $5^{\circ}$ da $\mathrm{CF} / 88$ dispõe que: "Todos são iguais perante a lei, sem distinção de qualquer natureza, garantindo-se aos brasileiros e aos estrangeiros residentes no País a inviolabilidade do direito à vida, à liberdade, à igualdade, à segurança e à propriedade $[. . .]^{24 "}$ " (destaque do autor) - é também uma abordagem da Carta Magna aplicável a este tema, destacando-se o direito à vida e à segurança. Direitos que são lesados diretamente ao se disponibilizarem nas gôndolas de supermercados, feiras e quitandas alimentos contaminados com agrotóxicos.

Ainda na $\mathrm{CF} / 88$ sobressaem os artigos $7^{\circ}$, inciso IV, que trata dos direitos do trabalhador, e o artigo 227, que incube à família, ao Estado e à sociedade a obrigatoriedade de providenciar às crianças o direito a alimentação.

Em âmbito infraconstitucional, é primordial a Lei n. 11.346/2006 - a Lei Orgânica de Segurança Alimentar ${ }^{25}$. O papel dessa lei é esclarecer os contornos do Sistema Nacional de Segurança Alimentar e Nutricional (Sisan), principalmente em seus artigos $2^{\circ}$ e $3^{\circ}$ :

Art. $2^{\circ}$ A alimentação adequada é direito fundamental do ser humano, inerente à dignidade da pessoa humana e indispensável à realização dos direitos consagrados na Constituição Federal, devendo o poder público adotar as políticas e ações que se façam

\footnotetext{
${ }^{23}$ OLIVEIRA, Gustavo Henrique Justino de. Direito ao desenvolvimento na Constituição brasileira de1988. Revista Eletrônica de Direito Administrativo Econômico, Salvador, n. 18, nov./dez./jan. 2009

${ }^{24}$ BRASIL. Constituição da República Federativa do Brasil de 1988, cit.

${ }^{25}$ BRASIL. Lei n. 11.346, de 15 de setembro de 2006. Cria o Sistema Nacional de Segurança Alimentar e Nutricional - SISAN com vistas em assegurar o direito humano à alimentação adequada e dá outras providências. Disponível em: <http://www.planalto.gov.br/ccivil_03/_ato2004-2006/2006/lei/l11346. htm>. Acesso em: 31 jan. 2017.
} 
necessárias para promover e garantir a segurança alimentar e nutricional da população.

[...]

Art. $3^{\circ} \mathrm{A}$ segurança alimentar e nutricional consiste na realização do direito de todos ao acesso regular e permanente a alimentos de qualidade, em quantidade suficiente, sem comprometer o acesso a outras necessidades essenciais, tendo como base práticas alimentares promotoras de saúde que respeitem a diversidade cultural e que sejam ambiental, cultural, econômica e socialmente sustentáveis ${ }^{26}$.

Todavia, em função do tema deste artigo, também devem ser citados os artigos $4^{\circ}$ e $8^{\circ}$ :

Art. $4^{\circ}$ A segurança alimentar e nutricional abrange:

[...]

III - a promoção da saúde, da nutrição e da alimentação da população, incluindo-se grupos populacionais específicos e populações em situação de vulnerabilidade social;

IV - a garantia da qualidade biológica, sanitária, nutricional e tecnológica dos alimentos, bem como seu aproveitamento, estimulando práticas alimentares e estilos de vida saudáveis que respeitem a diversidade étnica e racial e cultural da população; $\mathrm{V}$ - a produção de conhecimento e o acesso à informação; $[\ldots]^{27}$. (destaques do autor)

O artigo $4^{\circ}$ agrupa na definição de segurança alimentar os três direitos fundamentais que são lesados pela presença de resíduos de agrotóxicos nos alimentos comercializados. Já o artigo 8º inciso II da Lei n. 11.346/2006 determina que o Sisan reger-se-á pela "preservação da autonomia e respeito à dignidade das pessoas"28.

Esse inciso é o corolário de todos os direitos fundamentais. A junção de todos os direitos fundamentais explícitos, implícitos, descobertos e a serem descobertos resulta no exercício da dignidade humana. Portanto, pode-se afirmar que essa lei, em plena consonância constitucional, exige o fornecimento de alimentos isentos de contaminantes - fato que determina a ilegalidade da presença de agrotóxicos nos alimentos e a omissão do Estado em solucionar definitivamente tal agressão aos direitos. A omissão é ainda agravada porque o próprio Estado realizou as pesquisas que constatam a constância da contaminação ano após ano.

Também é plenamente aplicável ao caso o Código de Defesa do Consumidor, que em seu artigo $4^{\circ}$ determina como objetivos da Política Nacional das Relações de Consumo:

\footnotetext{
${ }^{26}$ LOPES, Ana Maria D’Avila; CHEHAB, Isabelle Maria Vasconcelos. op. cit. p. 97.

${ }^{27}$ BRASIL. Lei n. 11.346, de 15 de setembro de 2006, cit.

${ }^{28}$ Id. Ibid.
} 
[...] o atendimento das necessidades dos consumidores, o respeito à sua dignidade, saúde e segurança, a proteção de seus interesses econômicos, a melhoria da sua qualidade de vida, bem como a transparência e harmonia das relações de consumo $[\ldots]^{29}$.

Esse caput explicita que o legislador consumerista torna o Estado responsável por atender as necessidades do consumidor. É salutar que esse atendimento não se confunda com a Assistência Social; trata-se, sim, de atender as necessidades enquanto consumidor, ou seja, o lado mais frágil na relação de consumo e que necessita da ação estatal para que um equilíbrio justo seja mantido entre os envolvidos.

Deve ser também zelo do Estado garantir a dignidade, a saúde e a segurança do consumidor, temas completamente imbricados com o tema da presença irregular de agrotóxicos nos alimentos in natura.

As relações de consumo também devem caminhar para a melhoria da qualidade de vida do consumidor, tornando-se óbvio que o fornecimento de alimentos saudáveis e seguros deve ser perseguido constantemente pelos produtores e comerciantes para a execução efetiva dessa lei.

Enfim, a relação consumerista deve ser transparente e harmônica, ou seja, ao consumidor deve se informar quais agrotóxicos foram utilizados na produção e qual o período das respectivas aplicações. Dessa forma, o consumidor pode escolher livremente se adquire e consume tais produtos.

O mesmo dispositivo, em seu inciso II, apregoa que é um princípio da Política Nacional das Relações de Consumo que as ações governamentais devem proteger efetivamente o consumidor. Ora, as pesquisas governamentais constam a presença irregular e perigosa de vários agrotóxicos nos alimentos, portanto deve-se contar com a imediata atuação do Estado protegendo o consumidor, especialmente com informações sobre essa realidade, a custo de ocorrer um descumprimento estatal de tal princípio protetivo.

Outros dispositivos dessa lei podem ser aplicados à situação fática da presença dos agrotóxicos para proteger o consumidor mais efetivamente. Todavia, este tema tornar-se-ia um artigo à parte e de maior volume do que este. Assim, concentramo-nos em concluir este item como artigo $6^{\circ}$, inciso I, que garante como direito básico do consumidor "a proteção da vida, saúde e segurança contra os riscos provocados por práticas no fornecimento de produtos e serviços considerados perigosos ou nocivos ${ }^{30}$ ". Ou seja, a situação encontrada pelo programa PARA é

\footnotetext{
${ }^{29}$ BRASIL. Lein. 8.078, de 11 de setembro de 2008. Dispõe sobre a proteção do consumidor e dá outras providências. Disponível em: <http://www.planalto.gov.br/ccivil_03/leis/L8078compilado.htm>. Acesso em: 31 jan. 2017.

${ }^{30}$ BRASIL. Lei n. 8.078, de 11 de setembro de 2008 , cit.
} 
uma afronta à legislação da relação de consumo, tornando-se exigível uma atuação do Ministério Público para sua correção.

Devido à opção da Emenda Constitucional n. 45/2004 (EC n. 45/2004), artigo 10, "os tratados e convenções internacionais sobre direitos humanos que forem aprovados, em cada Casa do Congresso Nacional, em dois turnos, por três quintos dos votos dos respectivos membros, serão equivalentes às emendas constitucionais" 31 . Portanto, são integrados ao tema, a partir de 2004, os tratados internacionais.

Note-se que, cumprido o formalismo do artigo $1^{\circ}$ da EC n. 45/2004 e em se tratando de direitos humanos, serão emendas constitucionais. Não cumprido esse formalismo e tratando-se de direitos humanos, estes terão status supra legal ${ }^{32}$.

Atualmente, no Brasil existem, entre outros, os seguintes instrumentos internacionais que normatizam o direito à alimentação adequada:

(a) Declaração Universal dos Direitos Humanos:

Artigo $3^{\circ}$ Todo indivíduo tem direito à vida, à liberdade e à segurança pessoal.

[...]

Artigo $25^{\circ}$

1. Toda pessoa tem direito a um nível de vida suficiente para lhe assegurar e à sua família a saúde e o bem-estar, principalmente quanto à alimentação, ao vestuário, ao alojamento, à assistência médica e ainda quanto aos serviços sociais necessários, e tem direito à segurança no desemprego, na doença, na invalidez, na viuvez, na velhice ou noutros casos de perda de meios de subsistência por circunstâncias independentes da sua vontade ${ }^{33}$. (destaques do autor)

(b) Pacto Internacional dos Direitos Econômicos, Sociais e Culturais:

Artigo 11. [...] \$1. Os Estados-Partes no presente Pacto reconhecem o direito de toda pessoa a um nível de vida adequado para si próprio e para sua família, inclusive à alimentação, vestimenta e moradia adequadas, assim como uma melhoria contínua de suas condições de vida. Os Estados-partes tomarão medida

${ }^{31}$ BRASIL. Emenda Constitucional n. 45, de 30 de dezembro de 2004. Altera dispositivos dos arts. 5 $, 36,52,92$, 93, 95, 98, 99, 102, 103, 104, 105, 107, 109, 111, 112, 114, 115, 125, 126, 127, 128, 129, 134 e 168 da Constituição Federal, e acrescenta os arts. 103-A, 103B, 111-A e 130-A, e dá outras providências. Disponível em: <http://www.planalto.gov.br/ccivil_03/constituicao/emendas/emc/emc45.htm>. Acesso em: 31 jan. 2017.

${ }^{32} \mathrm{RE}$ 466.343, rel. min. Cezar Peluso, voto do min. Gilmar Mendes, julgamento em 3-12-2008, Plenário, DJE de 5-6-2009, com repercussão geral. No mesmo sentido: RE 349.703, rel. p/ o ac. min. Gilmar Mendes, julgamento em 3-12-2008, Plenário, DJE de 5-6-2009. Vide: Al 601.832-AgR, rel. min. Joaquim Barbosa, julgamento em 17-3-2009, Segunda Turma, DJEde 3-4-2009; HC 91.361, rel. min. Celso de Mello, julgamento em 23-9-2008, Segunda Turma, DJE de 6-2-2009.

${ }^{33}$ UNESCO. Declaração Universal dos Direitos Humanos. Brasília, 1988. Disponível em: <http://unesdoc. unesco.org/images/0013/001394/139423por.pdf>. Acesso em: 31 jan. 2017. 
apropriadas para assegurar a consecução desse direito, reconhecendo, nesse sentido, a importância essencial da cooperação internacional fundada no livre consentimento.

$\$ 2$. Os Estados-Partes no presente Pacto, reconhecendo o direito fundamental de toda pessoa de estar protegida contra a fome, adotarão, individualmente e mediante cooperação internacional, as medidas, inclusive programas concretos, que se façam necessários para:

1. Melhorar os métodos de produção, conservação e distribuição de gêneros alimentícios pela plena utilização dos conhecimentos técnicos e científicos, pela difusão de princípios de educação nutricional e pelo aperfeiçoamento ou reforma dos regimes agrários, de maneira que se assegurem a exploração e a utilização mais eficazes dos recursos naturais ${ }^{34}$. (destaques do autor)

Destaca-se no parágrafo primeiro o compromisso que os Estados-Partes assumem de tomar medidas para a consecução desse direito. Portanto, já há no Brasil um compromisso de caráter supralegal de resolver o problema da qualidade dos alimentos em relação à contaminação com agrotóxicos.

$\mathrm{O}$ primeiro item do parágrafo $2^{\circ}$ transcreve o compromisso de melhorar os métodos de produção e conservação. Nesse aspecto, as técnicas de produção agroecológicas, sem agrotóxicos, deveriam estar à frente dos métodos de produção convencional. Enquanto ainda não há uma conversão da produção convencional para a agroecológica, os consumidores deveriam receber as devidas informações sobre os agrotóxicos utilizados na produção.

\section{Pacto de San José 35}

Não trata diretamente do direito à alimentação adequada, mas em seu artigo $4^{\text {o }}$, que versa sobre o direito à vida, proclama que este direito deve ser protegido por lei. Podemos abstrair para o caso em tela, concluindo que deve haver, por parte do Estado, uma produção normativa que determine formas de controle sobre os agrotóxicos aplicados nos alimentos para consumo in natura e de que essas aplicações sejam devidamente informadas aos consumidores. Nesse caso, o Legislativo deve atuar com uma revisão da necessidade de produção legislativa; o Executivo, através de decretos e portarias de seus órgãos de fiscalização e controle; já o Judiciário, com

\footnotetext{
${ }^{34}$ BRASIL. Decreto n. 591, de 6 de julho de 1992. Atos Internacionais. Pacto Internacional sobre Direitos Econômicos, Sociais e Culturais. Promulgação. Disponível em: <http://www.planalto.gov.br/ccivil_03/ decreto/1990-1994/d0591.htm>. Acesso em: 31 jan. 2017.

${ }^{35}$ BRASIL. Decreto $n$. 678, de 6 de novembro de 1992. Promulga a Convenção Americana sobre Direitos Humanos (Pacto de São José da Costa Rica), de 22 de novembro de 1969. Disponível em: <http://www. planalto.gov.br/ccivil_03/decreto/d0678.htm>. Acesso em: 31 jan. 2017.
} 
o exame da legislação atual e sua aplicação imediata para o exercício do direito; e o Ministério Público, fiscalizando as medidas para a efetividade desses direitos.

O direito à alimentação saudável ou adequada, assim como no caso do direito à saúde, é de autoexecutoriedade, ou seja, de aplicação imediata e cuja regulamentação infraconstitucional é somente para aprimorar sua execução, não dependendo dessas leis para ser exercida. Esses direitos também são contínuos e progressivos; em outras palavras, devem sempre ser aprimorados e mesmo intensificados para tornar efetivo o direito a uma existência digna.

Os direitos fundamentais não podem ser apequenados ou desconsiderados na interpretação direta da Constituição; na legislação infraconstitucional, eles não podem sofrer deterioração. Ocorrendo tal fato, estar-se-á diante de uma inconstitucionalidade de direito irrevogável.

Destaca-se também que, além de irrevogável, o direito à alimentação adequada - por ser um direito fundamental - assume outras características. É uma cláusula aberta, permitindo incorporar novas faculdades, sempre em prol da realização mais ampla e progressiva do direito. A exegese avoca regras próprias para propiciar a convivência com os demais direitos fundamentais. Para Marum, baseando-se em Cançado Trindade, desaparece a polêmica entre a teoria monista e dualista para explicar o confronto entre direito interno e internacional, pois a primazia passa a ser da norma mais favorável à vítima. O direito fundamental ostenta a imprescritibilidade, não podendo ser regulado por normas civilistas que resolvem a pendência em função do tempo sem sua requisição ${ }^{36}$.

\section{Fundamentalidade do direito à informação}

Ao tratar do direito à informação, a CF/88 determina em seu artigo $5^{\circ}$, inciso XIV, que "é assegurado a todos o acesso à informação e resguardado o sigilo da fonte, quando necessário ao exercício profissional" ${ }^{37}$. Também em seu artigo 220 traz que "a manifestação do pensamento, a criação, a expressão e a informação, sob qualquer forma, processo ou veículo não sofrerão qualquer restrição, observado o disposto nesta Constituição" ${ }^{38}$. Podemos perceber que os dois institutos possuem um respectivo vetor da garantia ao direito de informação, pois o primeiro assegura o direito de buscar a informação e o segundo refere-se ao direito de informar. Entretanto, para completar a ontologia desse direito, deve haver o direito de buscar, o de poder proporcionar e também o de receber as informações que possam ser importantes para o exercício de outros direitos fundamentais.

\footnotetext{
${ }^{36}$ MARUM, Jorge Alberto de Oliveira. op. cit, p. 117.

${ }^{37}$ BRASIL. Constituição da República Federativa do Brasil de 1988, cit.

${ }^{38}$ Id. Ibid.
} 
No caso das informações sobre os agrotóxicos aplicados na produção dos alimentos, faz-se necessário o terceiro componente do direito à informação. $\mathrm{O}$ consumidor não tem condições técnicas de buscar esses dados, então eles devem ser fornecidos pelo produtor ou comerciante dos alimentos. Somente nessa conjuntura o consumidor poderá, ao ler o rótulo com dados sobre os agrotóxicos, exercer seu direito de escolha quanto a consumir ou não determinado alimento.

Para Veruska Sayonara de Góis, não há essa lacuna na Constituição, pois a cidadania concretiza-se com o "direito de informar, informar-se e ser informado" 39 . Assim, emerge como direito necessário a apresentação das devidas informações nos alimentos que passaram por tratamentos químicos para chegarem às gôndolas e bancadas do varejo.

Já disse Paulo Affonso Leme Machado: “Ora, no direito ambiental e em sua organização administrativa deve-se estabelecer, sem ambiguidades, uma dupla mão de direção: direito de informação e dever de informação" ${ }^{40}$. O reconhecido mestre argumentava sobre o direito ambiental em geral, mas sua afirmação é totalmente aplicável ao direito de ser informado sobre os alimentos que estão contaminados, visto que tal tema perpassa o direito ambiental.

Machado também afirma que "não basta a Administração Ambiental analisar ou coletar dados e apontar resultados. O itinerário científico das análises deve ser mostrado aos interessados, sejam os proprietários da empresa, sejam as vítimas concretas ou potenciais do fato analisado" ${ }^{41}$.

Esta afirmação feita em 1985 torna-se, no atual momento constitucional do país, muito mais concreta, e sua aplicação deve ser imediata. Destaca-se, aqui, a falha do sistema estatal em verificar o enorme problema de contaminação e sua omissão de informar, de forma massiva, à população os riscos a que está exposta.

Ainda é possível construir a argumentação a partir da definição de direito fundamental. Estando o direito à informação entre os direitos fundamentais, os envolvidos devem estar em uma relação de igualdade. Entretanto, é claro que o consumidor, ao não receber os dados sobre os agrotóxicos aplicados, está em uma relação desequilibrada. Portanto, a efetivação desse direito exige que os dados sejam disponibilizados ao consumidor, e não que este deva buscá-los em recursos judiciais ou entrevistas com os produtores.

Para Miguel Ángel Ekmekdjian, o uso de agrotóxicos nos alimentos sem que se informe aos consumidores o uso e a possível presença dos mesmos é similar

\footnotetext{
${ }^{39}$ SAYONARA DE GÓIS, Veruska. Direito constitucional à informação: reflexões sobre garantias possíveis. Revista Direito e Liberdade, Mossoró, v. 3, n. 2, p. 702, set. 2006.

${ }^{40} \mathrm{MACHADO}$, Paulo Affonso Leme. Direito à informação ambiental. Revista de Direito Público, São Paulo, p. 76, jul./set. 1985.

${ }^{41}$ Id. Ibid., p. 77.
} 
ao tratamento que se dá a uma cobaia, pois esta não tem o direito de opinar sobre a terapêutica que lhe será aplicada ${ }^{42}$. $\mathrm{O}$ mesmo jurista lembra que o direito de ser informado é uma vertente de direito passivo, ou seja, há a necessidade de o Estado mover-se para que a informação seja propiciada ao consumidor ${ }^{43}$. Essa ação - a de informar - pode ser regulada por leis infraconstitucionais, decretos ou normativas dos órgãos ambientais.

No Brasil, a aparente lacuna constitucional dessa dimensão do direito à informação é suprida pelo Código do Consumidor, artigo $6^{\circ}$, inciso III, que comporta a afirmação dessa garantia ao determinar que: estão entre os direitos básicos do consumidor "a informação adequada e clara sobre os diferentes produtos e serviços, com especificação correta de quantidade, características, composição, qualidade, tributos incidentes e preço, bem como sobre os riscos que apresentem" ${ }^{44}$. O código consumerista estende e detalha a aplicação desse direito em seu artigo $8^{\circ}$ :

Os produtos e serviços colocados no mercado de consumo não acarretarão riscos à saúde ou segurança dos consumidores, exceto os considerados normais e previsíveis em decorrência de sua natureza e fruição, obrigando-se os fornecedores, em qualquer hipótese, a dar as informações necessárias e adequadas a seu respeito ${ }^{45}$.

E continua no artigo seguinte:

O fornecedor de produtos e serviços potencialmente nocivos ou perigosos à saúde ou segurança deverá informar, de maneira ostensiva e adequada, a respeito da sua nocividade ou periculosidade, sem prejuízo da adoção de outras medidas cabíveis em cada caso concreto ${ }^{46}$.

Portanto, conclui-se que está garantido ao consumidor o direito de ter informações sobre os agrotóxicos que foram aplicados nos produtos, mesmo em casos de uso regular dos mesmos.

\section{Fundamentalidade do direito à saúde}

Outra dimensão desta análise é o direito à saúde, que consta na Constituição e reflete-se sobre o direito de conhecer os agrotóxicos aplicados nos alimentos.

\footnotetext{
${ }^{42}$ ÁNGEL EKMEKDJIAN, Miguel. Tratado de derecho constitucional: anotada con legislación, jurisprudencia y doctrina: arts. 1 a 14. 20. ed. Buenos Aires: Depalma, 2000. t. 1.

${ }^{43}$ Id.Ibid., p. 52.

${ }^{44}$ BRASIL. Lei n. 8.078, de 11 de setembro de 2008, cit.

${ }^{45}$ Id. Ibid.

${ }^{46}$ Id. Ibid.
} 
A CF/88 inicia o tratamento à saúde definindo, dentro da estrutura estatal, os responsáveis por seu cuidado. $\mathrm{O}$ artigo 23, inciso II, define que todos os entes federativos (União, estados, Distrito Federal e municípios) são responsáveis pelo fornecimento desse direito ${ }^{47}$.

A função desses entes é proporcionar as condições para que as pessoas mantenham sua saúde, evitem as causas das doenças e possam utilizar recursos técnicos e pessoais para recuperar-se de enfermidade. Nesse sentido, esclarecedor é o artigo 196: "A saúde é direito de todos e dever do Estado, garantido mediante políticas sociais e econômicas que visem à redução do risco de doença e de outros agravos e ao acesso universal e igualitário às ações e serviços para sua promoção, proteção e recuperação" 48 .

A análise dos textos constitucionais permite perceber a relação entre o direito de ser informado sobre o uso de agrotóxicos nos alimentos e o direito à saúde. É um dever do Estado garantir a redução de riscos e as ações de proteção à saúde, e estas garantias seriam efetivadas com a obrigatoriedade do fornecimento das informações sobre o uso de agrotóxicos.

Em visão simplista, o mercado afirma que a presença da opção de produtos orgânicos garante esse direito aos consumidores. Entretanto, a realidade dos preços de produtos orgânicos não permite efetivar esse direito de escolha. Segundo reportagem da Folha de São Paulo em julho de 2015, as diferenças de preços podem chegar a $270 \%$ entre convencionais e orgânicos ${ }^{49}$.

A mesma reportagem conclui que os preços poderão diminuir gradativamente com o aumento no consumo dos orgânicos e o consequente acréscimo da produção em escala. Ter-se-ia, assim, a realização das previsões dadas por Adam Smith sobre a mão invisível do mercado - enfim, não haveria necessidade de determinação legal para resolver esse problema.

Entretanto, não é esta a perspectiva. Com a atual condução do mercado de orgânicos, seus preços os tornam inacessíveis à grande maioria. Criaram-se duas cadeias produtivas: a de produtos convencionais e de orgânicos. A primeira abastece a maioria da população e desfruta da preferência por ter menores custos no mercado. A produção orgânica, por sua vez, é apresentada como complexa e de difícil obtenção, portanto um produto de elite $e^{50}$.

\footnotetext{
${ }^{47}$ BRASIL. Constituição da República Federativa do Brasil de 1988, cit.

${ }^{48}$ Id. Ibid.

${ }^{49}$ PREÇO alto ainda limita consumo de orgânicos; diferença chega a 270\%. Folha de S. Paulo. Seção mercado. Disponível em: <http://www1.folha.uol.com.br/mercado/2015/07/1661852-preco-alto-aindalimita-consumo-de-organicos-diferenca-chega-a-270.shtml>. Acesso em: 24 fev. 2016.

${ }^{50} \mathrm{FREITAS}, \mathrm{C}$. A. et al. Um estudo preliminar sobre a viabilidade do sistema de produção orgânico baseado em suas características económicas. In: CONGRESSO BRASILEIRO DE ECONOMIA E SOCIOLOGIA RURAL, 43. Anais... Ribeirão Preto: SOBER, 2005. CD-ROM.
} 
Essa construção também permite visualizar um processo discriminatório, pois o alimento de qualidade somente pode ser consumido regularmente por um percentual da população que tenha recursos financeiros suficientes.

Sabendo que a nutrição é base de uma boa saúde, os próprios informativos oficiais do governo federal indicam a boa alimentação como forma de prevenção contra o câncer ${ }^{51}$, e a Anvisa salienta que, para haver uma alimentação saudável, é preciso que ela seja "segura para o consumo, ou seja, estar livre de contaminação" ${ }^{52}$. Portanto, o papel do Estado, intermediando a relação entre capital e sociedade, não pode ser neutro. O Estado deve ser o responsável pelo equilíbrio de forças que atuam na sociedade, com uma normatização mais efetiva sobre o assunto ${ }^{53}$.

Sobre a indivisibilidade ou integralidade dos direitos humanos, Flávia Piovesan e Alessandra Gotti afirmam que o reconhecimento integral dos direitos humanos (fundamentais quando reconhecidos pela Constituição do país) pode conduzir a efetivação real de cada um deles ${ }^{54}$. Aplicando esta afirmação a nossa realidade, não é possível ver o direito à saúde sendo exercido em sua plenitude sem o direito de ser informado sobre o que está sendo utilizado na alimentação.

Piovesan e Gotti destacam ainda o Comentário n. 14 do Comitê de Direitos Econômicos, Sociais e Culturais, que esclarece quais obrigações os Estados signatários do Pacto Internacional de Direitos Econômicos, Sociais e Culturais devem cumprir. Entre eles estão o de providenciar as condições básicas determinantes da saúde, como a alimentação e a nutrição. Esse mesmo Comitê recomenda que o acesso à informação sobre os problemas da saúde seja propiciado à sociedade.

Com facilidade encontraremos muitos outros trabalhos especializados que defenderão de forma insuperável o direito à saúde como direito fundamental e de cumprimento imediato, pois, segundo o parágrafo $1^{\circ}$ do artigo $5^{\circ} \mathrm{da} \mathrm{CF} / 88$, "as normas definidoras dos direitos e garantias fundamentais têm aplicação imediata" 55 .

Diante dos direitos à alimentação saudável, à informação e à saúde, observa-se um engrenar entre os três no caso fático dos alimentos contaminados

\footnotetext{
${ }^{51}$ BRASIL. Ministério da saúde. Câncer: a informação pode salvar vidas, 2012. Disponível em: <http://www1. inca.gov.br/inca/Arquivos/alimentacao.pdf>. Acesso em: 10 abr. 2015.

${ }^{52}$ ANVISA. Alimentação saudável: fique esperto. 2. ed. Brasília, 2008. Disponível em: <http://www.anvisa. gov.br/propaganda/alimento_saudavel_gprop_web.pdf>. Acesso em: 10 abr. 2015.

${ }^{53}$ VITA, Leticia. Modelos de Estado y derecho a la salud en Argentina: descubriendo los presupuestos políticos de un sistema estructuralmente desigualitario. In: CLÉRICO, Laura; RONCONI, Liliana; ALDAO, Martín (Coords.). Tratado de derecho a la salud. Buenos Aires: Abeledo Perrot, 2013. p. 17-63.

${ }^{54}$ PIOVESAN, Flávia; GOTTI, A. P. Protección del derecho a la salud en el sistema de protección universal de los derechos humanos. In: CLÉRICO, Laura; RONCONI, Liliana; ALDAO, Martín (Coords.). Tratado de derecho a la salud. Buenos Aires: Abeledo Perrot, 2013. v. 1, p. 721-760.

${ }^{55}$ BRASIL. Constituição da República Federativa do Brasil de 1988, cit.
} 
com agrotóxicos e vendidos sem o conhecimento do consumidor. Como se trata de direitos fundamentais, devem ser garantidos e efetivados.

Também é importante lembrar-se do funcionamento sistêmico dos direitos fundamentais, ou seja, eles são interligados em sua concretização, e ferir um deles consiste no comprometimento dos outros. Nas palavras de Flávia Piovesan: "em suma, todos os direitos humanos constituem um complexo integral, único e indivisível, em que os diferentes direitos estão necessariamente inter-relacionados e são interdependentes entre si" $^{\text {"56. }}$.

\section{Por que as informações sobre agrotóxicos não estão disponíveis aos consumidores?}

Portanto, sobrevém a questão: diante de tal clareza do direito e da seriedade da situação, por que tais informações ainda não estão nos alimentos comercializados? A primeira possibilidade seria a falta de regulamentação para que os comerciantes e produtores disponibilizem essas informações. A outra resposta seria a intenção de preservar interesses econômicos. Esta parece ser a mais óbvia. Mas interesses de quem?

Não são os produtores ou comerciantes os maiores beneficiados com esse mercado contaminado de alimentos. São eles também vítimas de outro grupo que se beneficia desta situação: as empresas produtoras dos agrotóxicos.

As empresas que produzem os agroquímicos abarcam grande parte dos lucros finais da produção, pois boa parte da estrutura produtiva atual é dependente da aplicação de agroquímicos (fertilizantes e agrotóxicos). É um mercado de aproximados oito bilhões de dólares por ano no Brasil e concentra-se nas mãos do grupo composto por: Monsanto, Basf, Syngenta, Dupont, Bayer e Dow ${ }^{57}$.

\section{Pode ser feita alguma coisa?}

É um problema que deve ser atacado em várias frentes, e a primeira possibilidade seriam as soluções legislativas. No Brasil há registro de um projeto de lei para obrigar produtores e comerciantes a disponibilizarem alguma informação aos consumidores. Foi proposta na Assembleia Legislativa do Rio Grande do Sul pela deputada Marisa Formolo no mandato de 2011 a 2014.

\footnotetext{
${ }^{56}$ PIOVESAN, Flávia. Direitos humanos e o direito constitucional internacional. 3. ed. São Paulo: Max Limonad, 1997. p. 161.

${ }^{57}$ Situação do mercado de agrotóxicos no mundo e no Brasil, segundo fontes oficiais de diversos estudos realizados por: Banco Nacional de Desenvolvimento Econômico e Social (BNDES), Federação das Indústrias de São Paulo (Fiesp), Sindicato das Indústrias de Defensivos Agrícolas, Departamento Intersindical de Estatística e Estudos Socioeconômicos (Dieese), Anvisa e Campanha Nacional Contra o Uso de Agrotóxicos e Pela Vida (São Paulo, maio de 2012).
} 
Basicamente a lei exigiria que os produtos alimentícios que tiveram algum contato com agrotóxicos em seu ciclo produtivo apresentassem no rótulo "produzido com agrotóxicos" 58 .

Na justificativa do projeto de lei, a parlamentar salientou que a alimentação pode ser fonte de saúde ou doença e que há comprovações de pesquisa epidemiológicas relacionando os agrotóxicos à maior incidência de inúmeras doenças.

Entretanto, as leis estaduais enfrentam problemas quando interferem na competência legislativa da União. Sarlet e Fensterseifer ${ }^{59}$ analisaram as decisões do Supremo Tribunal Federal (STF) pela inconstitucionalidade de leis estaduais que interferiam na comercialização e no armazenamento de agrotóxicos. Segundo os ministros da Corte, os estados invadiram espaço de exclusividade da União em legislar. Entretanto, para os autores há nesses casos um forte componente econômico que motiva as grandes empresas (especialmente multinacionais) a levarem tais questões ao STF.

Sarlet e Fensterseifer ${ }^{60}$ acreditam que tais decisões, da década de 1980, poderiam ser diferentes com a atual formação do Supremo Tribunal Federal. Entretanto, em decisões recentes, o STF voltou a confirmar que os Estados não devem legislar a respeito de comércio de produtos estrangeiros, mesmo no caso dos agrotóxicos ${ }^{61}$.

Também é essencial o protagonismo do consumidor, com a conscientização do risco a que todos ficam expostos devido à invisibilidade dos agrotóxicos nos alimentos ${ }^{62}$. Essa atuação pode ser via uma ação civil pública, própria para proteger direitos difusos, coletivos e individuais homogêneos ${ }^{63}$.

As medidas devem ser ações intersetoriais e interministeriais, que articulem as esferas municipal, estadual e federal, sobre um tema que também é interdisciplinar, multidisciplinar e multiprofissional.

O Executivo deveria promover campanhas para estimular os produtores e comerciantes de sua responsabilidade legal e humanitária sobre a qualidade dos

\footnotetext{
${ }^{58}$ FORMOLO, Marisa. Proposição: PL 99 2013. Disponível em: <http://www.al.rs.gov.br/legislativo/ ExibeProposicao/tabid/325/SiglaTipo/PL/NroProposicao/99/AnoProposicao/2013/Default.aspx>. Acesso em: 10 abr. 2015.

${ }^{59}$ SARLET, Ingo Wolfgang; FENSTERSEIFER, Tiago. Direito constitucional ambiental: constituição, direitos fundamentais e proteção do ambiente. 4. ed. São Paulo: Ed. Revista dos Tribunais, 2014.

60Id. Ibid.

${ }^{61}$ ADI 3852 / SC - SANTA CATARINA. AÇÃO DIRETA DE INCONSTITUCIONALIDADE. Relator(a): Min. DIAS TOFFOLI. Julgamento: 07/10/2015 Órgão Julgador: Tribunal Pleno. Publicação ACÓRDÃO ELETRÔNICO. DJe-249 DIVULG 10-12-2015 PUBLIC 11-12-2015.

${ }^{62}$ GALINDO, Flávia; PORTILHO, Fátima. op. cit., p. 83.

${ }^{63}$ MARINONI, Luiz Guilherme; ARENHART, Sérgio Cruz; MITIDEIRO, Daniel. Curso de processo civil: tutela dos direitos mediante procedimentos diferenciados. São Paulo: Ed. Revista dos Tribunais, 2105. v. 3.
} 
alimentos ${ }^{64}$, bem como aumentar e melhorar o financiamento e a assistência técnica para produção de orgânicos.

O Ministério Público poderia agir na fiscalização jurídica e ter atuação conjunta com os órgãos responsáveis pela fiscalização técnica - atuação indicada por Machado já em 1985.

Sarlet et al., ao comentarem sobre a importância de outras prestações que o Estado deve providenciar para as pessoas alcançarem o mínimo existencial, afirmaram:

[...] que se cuidar de prestações indispensáveis para qualquer pessoa resulta inquestionável, de tal sorte que não se deveria, em princípio, questionar que se está diante de bens jusfundamentais assegurados direta ou indiretamente pela ordem constitucional ${ }^{65}$.

Aplicando a situação em tela, temos uma relação de direitos fundamentais: informação, saúde e alimentação adequada, que se imbricam em um condicionante para a vida e para a vida com dignidade, devendo, portanto, receber toda a proteção do Estado e da sociedade em geral, à luz da Constituição ${ }^{66}$. Os autores, resgatando João Loureiro, lembram que há uma sobreposição de esferas a serem protegidas conjuntamente ${ }^{67}$, o que torna as atuações nesse caso um conjunto único, inseparáveis na prática.

Segundo ampla jurisprudência do STF, é responsabilidade conjunta dos entes federados em prestar assistência à saúde ${ }^{68}$. As causas fáticas dessa decisão do Supremo são sobre a prestação de medicamentos de alto valor e que não são fornecidos pela rede pública. Entretanto, podemos também transpor o mesmo raciocínio para encontrar o responsável pela fiscalização dos produtores e pela informação do consumidor a respeito dos alimentos contaminados por agrotóxicos. Entretanto, salienta-se que a União, por meio de suas agências, possui uma estrutura muito mais adequada para a pesquisa dos contaminantes e sua divulgação. Ainda assim, a atuação nas notificações e na educação ambiental pode ser feita pelos Estados e Municípios.

Enfim, não se pode desprezar a mudança de concepção cosmológica da produção de alimentos. Ela é muito mais que uma atividade econômica para gerar commodities. Segundo Juliana Santilli,

\footnotetext{
${ }^{64}$ BRASIL. Secretaria de Direitos Humanos da Presidência da República. Direito à alimentação adequada. Brasília: Coordenação Geral de Educação em SDH/PR, Direitos Humanos, Secretaria Nacional de Promoção e Defesa dos Direitos Humanos, 2013. 80 p., il. - (Por uma cultura de direitos humanos).

${ }^{65}$ SARLET, Ingo Wolfgang; MARINONI, Luiz Guilherme, MITIDIERO, Daniel. Curso de Direito Constitucional. 3. ed., rev., atual. e ampl. São Paulo: Ed. Revista dos Tribunais, 2014. p. 596.

${ }^{66}$ Id. Ibid.

${ }^{67}$ Id. Ibid., p. 592.

${ }^{68}$ ARE 906454 AgR / RS - RIO GRANDE DO SUL AG.REG. NO RECURSO EXTRAORDINÁRIO COM AGRAVO. Relator(a): Min. ROSA WEBER. Julgamento: 02/02/2016 Órgão Julgador: Primeira Turma. Publicação: PROCESSO ELETRÔNICO DJe-034 DIVULG 23-02-2016 PUBLIC 24-02-2016, entre outros.
} 
É relevante citar que os ecossistemas agrícolas são constituídos por interações entre fatores bióticos, abióticos e antrópicos. A participação humana é impregnada de sua história e cultura. Assim, o ecossistema no enfoque da agrobiodiversidade é também uma manifestação cultural e socioeconômica. Portanto, a sua preservação inclui, obrigatoriamente, o resgate e a manutenção da cultura e história socioeconômica dos agentes envolvidos e do local em que foi e tem sido desenvolvido. Este seria o quarto nível de variabilidade (os outros são: diversidade biológica, genética e ecológica ${ }^{69}$.

Partindo desse pressuposto, pode-se afirmar que a agricultura é também fonte de vida, de história e de biodiversidade - uma biodiversidade formada a partir da natureza e da atuação histórica do homem, trazendo em cada "cultura vegetal" a "cultura humana". Assim, o resgate das formas tradicionais de agricultura e alimentação, o abandono do mero "pacote tecnológico" das multinacionais, coloca a humanidade mais próxima da natureza e de sua história e a salvo desse envenenamento crônico que se encontra atualmente.

\section{Conclusões}

Do apresentado, conclui-se que o direito à informação e, consequentemente, o direito à saúde do consumidor estão sendo lesados com a situação atual da comercialização de alimentos in natura produzidos com agrotóxicos.

É retirado das pessoas o poder de escolha, pois não estão informadas sobre a qualidade e a origem dos produtos que estão adquirindo e consumindo. Portanto, há também o comprometimento da liberdade do consumidor.

Unindo os direitos fundamentais explícitos e implícitos da Constituição brasileira e o Código de Proteção ao Consumidor, a resposta para o problema apresentado deve ser a obrigatoriedade de comerciantes e produtores exporem nos produtos o que foi aplicado em sua produção, independentemente de usarem as dosagens recomendadas e no período correto.

O embaraço para que essa necessidade não tenha sido atendida até então parece ser mais de cunho econômico do que técnico. Portanto, os interessados há de ser chamados para discutir uma solução. São eles os consumidores, os produtores, os comerciantes e as indústrias que produzem e comercializam os agrotóxicos. Estas devem arcar com os possíveis custos da solução, pois são a fonte inicial da geração dessa externalidade da atividade econômica.

\footnotetext{
${ }^{69}$ SANTILLI, Juliana. A agrobiodiversidade e o Sistema Nacional de Unidades de Conservação da natureza (SNUC). Revista Magister de Direito Ambiental e Urbanístico, Porto Alegre, ano 6, n. 32, p. 5-33, out./nov. 2010.
} 
Saúde e direito à informação: o problema dos agrotóxicos nos alimentos

\section{Referências}

ABBOUD, Georges; CARNIO, Henrique Garbellini; OLIVEIRA, Rafael Tomaz de. Introdução à teoria e à filosofia do direito. 2. ed. São Paulo: Thomson Reuters, 2014.

ÁNGEL EKMEKDJIAN, Miguel. Tratado de derecho constitucional: anotada con legislación, jurisprudencia y doctrina: arts. 1 a 14. 20. ed. Buenos Aires: Depalma, 2000. t. 1.

ANVISA. Alimentação saudável: fique esperto. 2. ed. Brasília, 2008. Disponível em: <http:// www.anvisa.gov.br/propaganda/alimento_saudavel_gprop_web.pdf $>$. Acesso em: 10 abr. 2015.

. Programa de Análise de Resíduos de Agrotóxicos em Alimentos: relatório de atividades de 2011 e 2012. Brasília, 29 out. 2013.

Programa de Análise de Resíduos de Agrotóxicos em Alimentos: relatório de atividades de 2010. Brasília, 05 dez. 2011.

BRASIL. Ministério da saúde. Câncer: a informação pode salvar vidas, 2012. Disponível em: $<$ http://www1.inca.gov.br/inca/Arquivos/alimentacao.pdf>. Acesso em: 10 abr. 2015.

Ministério da Saúde. Secretaria de Vigilância em Saúde. Programa Nacional de DST/AIDS. Manual clínico de alimentação e nutrição na assistência a adultos infectados pelo HIV / Ministério da Saúde, Secretaria de Vigilância em Saúde, Programa Nacional de DST/Aids. - Brasília: Ministério da Saúde, 2006. 88 p. (Série A. Normas e Manuais Técnicos).

. Secretaria de Direitos Humanos da Presidência da República. Direito à alimentação adequada. Brasília: Coordenação Geral de Educação em SDH/PR, Direitos Humanos, Secretaria Nacional de Promoção e Defesa dos Direitos Humanos, 2013. 80 p., il. - (Por uma cultura de direitos humanos).

BRITO FILHO, José Claudio Monteiro de. Trabalho com redução do homem à condição análoga à de escravo e dignidade da pessoa humana. Texto revisto e com alterações. Publicado originalmente na Revista Genesis, Curitiba, n. 137, p. 673-682, maio. 2004. Disponível em: $<$ http://www.oit.org.br/sites/all/forced_labour/brasil/documentos/dignidadetrabalhoescravo. pdf $>$. Acesso em 25 fev. 2016.

CARVALHO, Délton Winter de. A sociedade do risco global e o meio ambiente como um direito personalíssimo intergeracional. Revista de Direito Ambiental, São Paulo, v. 13, n. 52, p. 27-36, out./dez. 2008.

FORMOLO, Marisa. Proposição: PL 99 2013. Disponível em: <http://www.al.rs. gov.br/legislativo/ExibeProposicao/tabid/325/SiglaTipo/PL/NroProposicao/99/ AnoProposicao/2013/Default.aspx>. Acesso em: 10 abr. 2015.

FREITAS, C. A. et al. Um estudo preliminar sobre a viabilidade do sistema de produção orgânico baseado em suas características económicas. In: CONGRESSO BRASILEIRO DE ECONOMIA E SOCIOLOGIA RURAL, 43. Anais... Ribeirão Preto: SOBER, 2005. CD-ROM. 
GALINDO, Flávia; PORTILHO, Fátima. O Peixe Morre pela Boca: como os consumidores entendem os riscos dos agrotóxicos e dos transgênicos na alimentação. Sustentabilidade em Debate, Brasília, v. 6, n. 2, p. 73-87, maio/ago 2015.

JOSEFO, Flavio. Antiguidades judaicas. São Paulo: Paulus Ed., 2001.

LOPES, Ana Maria D’Avila; CHEHAB, Isabelle Maria Vasconcelos. A construção do direito fundamental à alimentação adequada no nordeste brasileiro. Revista de Direito Constitucional e Internacional, v. 68, jul./set. 2009.

MACHADO, Paulo Affonso Leme. Direito à informação ambiental. Revista de Direito Público, São Paulo, p. 75-95, jul./set. 1985.

MARINONI, Luiz Guilherme; ARENHART, Sérgio Cruz; MITIDEIRO, Daniel. Curso de processo civil: tutela dos direitos mediante procedimentos diferenciados. São Paulo: Ed. Revista dos Tribunais, 2105. v. 3.

MARUM, Jorge Alberto de Oliveira. Meio ambiente e direitos humanos. Revista de Direito Ambiental, v. 28, out./dez. 2002.

OLIVEIRA, Gustavo Henrique Justino de. Direito ao desenvolvimento na Constituição brasileira de1988. Revista Eletrônica de Direito Administrativo Econômico, Salvador, n. 18, nov./dez./jan. 2009.

PIOVESAN, Flávia. Direitos humanos e o direito constitucional internacional. 3. ed. São Paulo: Max Limonad, 1997.

; GOTTI, A. P. Protección del derecho a la salud en el sistema de protección universal de los derechos humanos. In: CLÉRICO, Laura; RONCONI, Liliana; ALDAO, Martín (Coords.). Tratado de derecho a la salud. Buenos Aires: Abeledo Perrot, 2013. v. 1, p. 721-760.

PREÇO alto ainda limita consumo de orgânicos; diferença chega a 270\%. Folha de S. Paulo. Seção mercado. Disponível em: <http://www1.folha.uol.com.br/mercado/2015/07/1661852-preco-altoainda-limita-consumo-de-organicos-diferenca-chega-a-270.shtml>. Acesso em: 24 fev. 2016.

SANTILLI, Juliana. Agrobiodiversidade e direitos dos agricultores. 2009. Tese (Doutorado) Pontifícia Universidade Católica, PUC/PR, Curitiba, 2009. 409 f.

A agrobiodiversidade e o Sistema Nacional de Unidades de Conservação da natureza (SNUC). Revista Magister de Direito Ambiental e Urbanistico, Porto Alegre, ano 6, n. 32, p. 5-33, out./nov. 2010.

SARLET, Ingo Wolfgang; FENSTERSEIFER, Tiago. Direito constitucional ambiental: constituição, direitos fundamentais e proteção do ambiente. 4. ed. São Paulo: Ed. Revista dos Tribunais, 2014.

; MARINONI, Luiz Guilherme, MITIDIERO, Daniel. Curso de Direito Constitucional. 3. ed., rev., atual. e ampl. São Paulo: Ed. Revista dos Tribunais, 2014. 
Saúde e direito à informação: o problema dos agrotóxicos nos alimentos

SAYONARA DE GÓIS, Veruska. Direito constitucional à informação: reflexões sobre garantias possíveis. Revista Direito e Liberdade, Mossoró, v. 3, n. 2, p. 689-704, set. 2006.

VEIGA, José Eli. Crescimento, agricultura e meio-ambiente. In: ENCONTRO NACIONAL DE ECONOMIA, 15. Anais... Recife, 1997. v. 2, p. 900-939.

VITA, Leticia. Modelos de Estado y derecho a la salud en Argentina: descubriendo los presupuestos políticos de un sistema estructuralmente desigualitario. In: CLÉRICO, Laura; RONCONI, Liliana; ALDAO, Martín (Coords.). Tratado de derecho a la salud. Buenos Aires: Abeledo Perrot, 2013. p. 17-63.

Tarcisio Miguel Teixeira - Doutorando em Direito Constitucional na Universidad Nacional de Buenos Aires; mestre em Agronomia pela Universidade Estadual de Maringá; especialista em Cultura de Tecidos Vegetais pela Universidade Federal de Lavras; graduado em Agronomia pela Universidade Estadual de Maringá; graduado em Biologia pela Universidade de Cuiabá; graduado em Direito pela Universidade do Sul de Santa Catarina. Umuarama/PR, Brasil. E-mail: tarcisio.teixeira@ifpr.edu.br. 